\title{
UMA LEITURA DWORKINIANA DO CONTROLE JUDICIAL DA REFORMA AGRÁRIA
}

\section{Horácio Lobato Neto ${ }^{1}$}

Resumo: Analisa se a reforma agrária pode ser levada a efeito por decisões judiciais. Inicia com a Teoria do Direito desenvolvida por Dworkin e sua reflexão sobre o controle judicial de políticas públicas a partir de construção argumentativa que inclui questões morais e propriamente políticas. Em seguida, passa-se ao estudo sobre o que seria a reforma agrária como política pública e como direito fundamental. Por fim, analisa como o Poder Judiciário vem se estruturando para lidar com a questão. Concluiu-se que o Poder Judiciário pode intervir na distribuição de terras, baseando-se em princípios, para salvaguardar direitos fundamentais.

Palavras-chave: Reforma agrária; controle judicial; política pública.

\section{A DWORKINIAN READING OF JUDICIAL CONTROL OF AGRARIAN REFORM}

Abstract: It analyzes whether agrarian reform can be carried out by judicial decisions. It begins with the Theory of Law developed by Dworkin and his reflection on the judicial control of public policies based on argumentative construction that includes moral and properly political issues. Then, we move on to the study of what agrarian reform would be as a public policy and as a fundamental right. Finally, it analyzes how the Judiciary has been structuring itself to deal with the issue. It was concluded that the Judiciary can intervene in the distribution of land, based on principles, to safeguard fundamental rights

Keywords: Land reform; judicial control; public policy.

\section{INTRODUÇÃO}

A desordem fundiária brasileira, causada por um conjunto de fatores históricos e estruturais que levaram à concentração de grandes áreas de terra nas mãos de poucos, a exemplo do complexo processo de grilagem ${ }^{2}$, ainda provoca vários problemas no campo, como a extrema violência e o desmatamento de grandes áreas verdes.

\footnotetext{
${ }^{1}$ Mestre e Doutorando no Programa de Pós Graduação em Direito da Universidade Federal do Pará, linha de pesquisa Direitos Humanos e Meio Ambiente. Email: hlobatoneto@yahoo.com.br.

2 A grilagem constitui na apropriação privada irregular ou ilegal de terras públicas. Segundo a publicação $A$ grilagem nas terras públicas da Amazónia brasileira do Ministério do Meio Ambiente (BRASIL, 2006, p. 11), costuma-se dizer que o termo grilagem tem sua origem na tentativa de transformar títulos falsificados, dandolhes aparência de legais, com o emprego do inseto ortóptero - o grilo - que era confinando junto de um documento falso, a fim de que seus excrementos the dessem um aspecto de envelhecido. Contudo, a grilagem consiste em outras diversas práticas, como fraudes em cartórios de registro de imóveis, processos judiciais, dentre outros, de modo a se justificar falar-se, hoje, em um complexo processo de grilagem. Para se ter uma
}

Revista de Direito Ambiental e Socioambientalismo | e-ISSN: 2525-9628 | Encontro Virtual | v. 7 | n. 1 | p. 20 - 39 | Jan/Jul. 2021. 
Tudo isso só faz com que seja cada vez mais necessário levar a efeito o comando constitucional da reforma agrária, na medida em que ela se revela, segundo Carter (2010, p. 68-69), como a política pública, por excelência, de combate a esses males.

A despeito dessa premente necessidade, o que se observou ao longo dos últimos anos foi a incapacidade de gerenciamento e de implementação por parte do Poder Executivo dessa política pública. Enquanto isso, o número de demandas judiciais envolvendo conflitos fundiários, cujo objeto é a posse ou propriedade de imóveis rurais ocupados por movimentos sociais ou grupos de trabalhadores rurais que lutam pela reforma agrária e que acabam, inclusive, em homicídios, vem crescendo consideravelmente nos últimos anos.

É nesse sentido que o presente artigo se propõe a analisar se a reforma agrária no Brasil, com assento constitucional, pode ser levada a efeito por meio de decisões judiciais, diante da inércia/omissão sintomática do Poder Executivo em realizá-la.

Essa análise será feita com base na Teoria do Direito do filósofo norte-americano Ronald Dworkin, desenvolvida durante o debate com o seu iminente professor, o filósofo inglês H. L. A. Hart, pelo fato de ele (Ronald Dworkin) ter dedicado profunda reflexão sobre o controle judicial de políticas públicas a partir de uma construção argumentativa que inclui, em sua concepção, questões morais e propriamente políticas, ao contrário do positivismo que vê nas regras o único elemento componente do direito (MACEDO JUNIOR, 2013, p. 158 e 198).

Para tanto, inicialmente será abordado o que Dworkin, nos diferentes momentos de sua produção intelectual, desenvolveu a título de controle judicial de políticas públicas. Após, passa-se ao estudo do que seria a reforma agrária como política pública e como direito fundamental. Por fim, analisar-se-á como o Poder Judiciário vem se estruturando para lidar com o assunto, uma vez que é instado, cada vez mais, a intervir na questão agrária.

noção da dimensão da grilagem, a Corregedoria das Comarcas do Interior do Tribunal de Justiça do Estado do Pará, por exemplo, ao longo das correições realizadas nos cartórios de registro de imóveis até 2007, constatou diversos indícios de irregularidades nas matrículas de imóveis rurais, o que ensejou, através do Provimento $\mathrm{n}^{\circ}$ 13/2016-CJCI/TJ/PA, o bloqueio administrativo das matrículas e, posterirormente, o cancelamento e encerramento dessas mesmas matrículas por orientação do Conselho Nacional de Justiça (CNJ), até a sobrevinda decisão de "requalificação administrativa do título causal dos registros cancelados" nos autos do mesmo Pedido de Providências (Processo $\mathrm{n}^{\circ}$ 000193-67.2009.2.00.0000). Essa drástica medida foi tomada a partir dos resultados dos estudos da Comissão Permanente de Monitoramento, Estudo e Assessoramento das Questões Ligadas à Grilagem criada pela Portaria n. 0271/2007-GP/TJE-PA, concluindo que somente a soma das áreas bloqueadas corresponderia a 90,2\% do tamanho total do território do Estado do Pará. Ou seja, 112.547.719,34 hectares dos 124.768.951,50 hectares do total do território do Estado do Pará estavam sob suspeita de irregularidades em relação à legalidade dos títulos de origem e aos registros imobiliários (isso sem contabilizar as sobreposições em áreas de unidades de conservação, terras indígenas e quilombolas e áreas militares). 
A análise que aqui se propõe foi construída ao longo de uma pormenorizada pesquisa de dados primários, a exemplo de relatórios oficiais e de organizações não-governamentais, levantamentos estatísticos e censos específicos sobre a questão fundiária no Brasil, além de dados secundários, preponderantemente de natureza bibliográfica e legislativa.

A importância deste artigo, em última medida, revela-se não apenas pela análise da Teoria do Direito de Ronald Dworkin, mas também pelo fato de que a reforma agrária representa, como anteriormente dito, uma importante política pública de combate às desigualdades e à pobreza no Brasil (CARTER, 2010, p. 46).

\section{O DIREITO PENSADO POR DWORKIN}

As teorias positivistas estão fundadas, basicamente, em dois elementos centrais, que são: i) a autoridade e a ii) hierarquia normativa. O primeiro veicula a ideia de que as normas jurídicas determinam as condutas dos cidadãos porque elas foram produzidas por uma autoridade com atribuição para tanto, sendo despiciendo investigar o seu conteúdo moral. Já o segundo elemento traz consigo a concepção de que as normas componentes de um sistema jurídico estão dispostas em grau de hierarquia, cujo objetivo é estabelecer qual delas prevalecerá em caso de eventual conflito (DIAS, 2016, p. 30).

Registre-se que na versão do positivismo desenvolvida por H. L. A. Hart na sua obra O Conceito de Direito, que foi considerada como uma das mais complexas dessa tradição do pensamento jurídico ${ }^{3}$, a Teoria do Direito se concentra na discussão de validade, de modo que os elementos que integram o sistema jurídico estão posicionados como vetores de validação de práticas sociais como regras.

Desse modo, só será considerada como regra a prática social que trilhar o caminho de um modelo de produção institucionalizado, a partir da ideia de que o direito estabelece o

\footnotetext{
${ }^{3}$ É o próprio Dworkin (2007a, p. 31 e 74) quem afirma que a versão do positivismo proposta por H. L. A. Hart é a mais complexa dentre todas até então desenvolvidas nessa tradição do pensamento jurídico, que segundo o filósofo norte-americano se assemelham por três teses, a saber: i) de que todas as comunidades têm um conjunto de regras por elas (comunidades) utilizadas para determinar os padrões de comportamento, e essas regras podem ser identificadas como válidas, diferenciando-as daquelas que não o são (a essa tese que Ronald Dworkin chamou de pedigree); ii) se dado caso estiver excluídos dessas regras que tem pedigree, a autoridade competente terá que decidi-lo de acordo com critérios alheios ao direito; e iii) das regras que tem pedigree decorrem as obrigações jurídicas às correspondem, em sentido oposto, os direitos, logo o caso que não tem previsão nessas regras implica dizer inexistir uma obrigação jurídica e um direito, que passariam a existir a partir do poder discricionário da autoridade competente quando o julgasse.
} 
padrão e o meio de reconhecimento de caráter obrigatório, de sorte a caracterizá-lo como um complexo de regras primárias e secundárias (HART, 2009, p. 105).

As normas primárias, consideradas como tipo básico, exigem que as pessoas pratiquem ou se abstenham de praticar determinados atos, independentemente de sua vontade. Impõem deveres e dizem respeito a atos que envolvem movimento físico ou mudanças físicas. No outro lado, as regras secundárias orbitam em torno daquelas e por isso são consideradas parasitárias, estabelecendo que os membros de uma determinada comunidade podem, ao fazer ou dizer certas coisas, produzir novas regras do tipo principal, extinguir ou modificar regras antigas ou determinar sua incidência e ainda controlar sua aplicação (HART, 2009, p. 105106).

Em outras palavras, as regras secundárias seriam metarregras, por se referirem ao reconhecimento, à alteração e à aplicação das regras primárias.

É discordando desse pensamento que Dworkin busca demonstrar que ao lado das regras (padrão normativo básico) os juristas raciocinam ou debatem acerca de direitos e obrigações, especialmente nos casos difíceis (os hard cases), recorrendo a outros tipos de padrões (standards), a exemplo de princípios e políticas (DWORKIN, 2007a, p. 35-36).

No artigo intitulado Modelo de Regras I, que mais tarde passou a integrar, como capítulo, a obra Levando os Direitos a Sério, Dworkin parte de dois casos emblemáticos da jurisprudência norte-americana para contra-argumentar a ideia de direito defendida por $\mathrm{H}$. L. A. Hart.

No primeiro caso, Riggs v. Palmer, a Corte nova-iorquina negou o direito, mesmo havendo uma lei que dispusesse de modo contrário, que o neto herdasse a herança do avô que ele mesmo matou. $\mathrm{O}$ fundamento para tanto foi o princípio segundo o qual ninguém pode se beneficiar da própria torpeza. De modo muito semelhante, no segundo caso, Henningsen $v$. Bloomfield, uma montadora de carros foi responsabilizada pela Corte de Nova Jersey além da previsão contratual em razão do acidente de carro que vitimou seus passageiros. Vários princípios foram usados para fundamentar essa decisão, incluindo o da proteção de contratos desproporcionais.

Esses dois casos serviram para Dworkin como evidências de que o direito não é apenas um conjunto de regras, sejam elas primárias ou secundárias, mas também de princípios e políticas, ou seja, de outros padrões além daqueles estritamente considerados pelo positivismo de então. 
Diante desses outros padrões existentes e ignorados pelo positivismo, Dworkin (2007a, p. 36) procura demonstrar a insuficiência da Teoria do Direito construída a partir dessa tradição do pensamento jurídico. Para tanto, deixa claro a relevância do papel desempenhado pelos princípios como "uma exigência de justiça ou equidade ou alguma outra dimensão da moralidade". A importância dos princípios, portanto, está atrelada a sua razoabilidade e justiça, a sua natureza substantiva (MACEDO JÚNIOR, 2013, p. 164).

Em se tratando de padrões do direito, a identificação e a análise do conteúdo dos princípios então passam a ser indispensáveis para o desenvolvimento da linha argumentativa proposta por Dworkin. Tomando por base os casos Riggs v. Palmer e Henningsen $v$. Bloomfield, tinha-se a noção de que os princípios correspondiam a exigências relacionadas a valores morais, sobretudo de justiça e equidade.

Nesse sentido, Dworkin reintroduz os debates morais na quadra jurídica, o que havia sido deixado de lado pelo positivismo, que pregava a inexistência de uma relação necessária do direito com a moral.

Dworkin então pretendeu estabelecer uma compreensão ampliada em relação aos recursos procedimentais puros, oferecendo uma alternativa ao monopólio estatal de produção de regras. Contudo, é necessário admitir que as regras não emanam apenas na forma de um comando de uma autoridade, mas, para além disso, elas representam as crenças e valores da comunidade política que as produziu. Por isso, a produção de normas não é exclusividade dos poderes constituídos. Os membros de uma dada comunidade política, por meio de práticas sociais racionais, também constroem padrões de comportamento (DIAS, 2016, p. 32-33).

\subsection{A DIFERENÇA ENTRE REGRAS E PRINCÍPIOS}

Dworkin (2007a, p. 37) tem como objetivo distinguir os princípios das regras, deixando evidente que na versão do positivismo que procura combater, o conceito de regra depende de considerações preliminares relacionadas à sua origem.

Dworkin (2007a, p. 32-33), assim como Hart (2009, p. 107) havia feito, deixa registrado a distinção entre duas possíveis formas de persuasão de uma norma jurídica: as ideias de dever e obrigação.

Dias (2016, p. 35) acredita que a relevância dessa distinção se deve ao fato de que a presença de uma regra de direito orienta a conduta e o comportamento do cidadão, 
considerando que ela é fruto de práticas sociais consolidadas e reconhecidas pelo "sistema de referenciação jurídica".

Na verdade Dworkin (2007a, p. 28 e 85) desejava repelir a tese de que as regras sociais se constituem no elemento principal da formação dos conteúdos das regras jurídicas e, para tanto, lança os seguintes argumentos: i) a prática social nem sempre dá causa a um dever, considerando que uma quantidade significativa desses deveres não se vincula a uma prática social consolidada; e ii) a teoria da regra social é incapaz de reconhecer a distinção entre dois tipos de moralidade social, que seriam a moralidade concorrente e a moral convencional. Pela primeira, os membros de uma comunidade política estão de acordo que determinados deveres precisam ser atendidos como regra normativa em função de seu próprio conteúdo e não porque há uma anuência geral e irrestrita. Já pela segunda há concordância ampla. Apenas nessa última a teoria da prática social poderia ser validamente invocada.

Nesse sentido, para Dworkin a teoria da regra social é imprestável para validar o fundamento de uma regra jurídica, sendo as práticas morais suas verdadeiras balizas e no modelo pensado pelo filósofo norte-americano as regras desempenham a manifestação formal dos poderes constituídos, tornando-se, pois, a via por meio da qual o sistema de organização política exterioriza a vontade coletiva (DIAS, 2016, p. 37).

Vale dizer que os poderes constituídos, embora promovam a produção de um padrão de comportamento obrigatório, não esgotam o fenômeno jurídico, de sorte que, em sua concepção ampla, o direito está estruturado sob diversas formas de produção normativa, que nem sempre são originárias dos poderes formalmente instituídos.

Assim, Dworkin (2007a, p. 39) pretende marcar a diferença conceitual entre os princípios e as regras, firmando uma distinção de ordem lógica entre essas espécies, sendo que cada uma delas apresenta uma orientação específica para uma dada situação que careça de decisão.

As regras, por exemplo, seriam aplicáveis à maneira do "tudo ou nada". Segundo Dworkin (2007a, p. 39) “dados os fatos que uma regra estipula, então ou a regra é válida, e neste caso a resposta que ela fornece deve ser aceita, ou não é válida, e neste caso em nada contribui para a decisão".

Interpretando essa lição, Dias (2016, p. 38) explica que, uma vez apresentadas as condições de aplicação, as regras oferecem uma solução imediata que deve ser acatada ou refutada em sua inteireza, sendo inadmissíveis juízos parciais. 
Do outro lado, os princípios não apresentam consequências jurídicas que se seguem automaticamente quando as condições são dadas. Eles enunciam uma razão que conduz o argumento numa certa direção, mas que reclama uma decisão particular (DWORKIN, 2007a, p. 41).

Macedo Júnior (2013, p. 164) ensina que “os princípios funcionam segundo uma gramática lógica que exige algum tipo de ponderação - e, portanto, prática argumentativa e de justificação - e envolvem a referência a um valor como o seu foco intencional determinante".

Os princípios, portanto, não se aplicam segundo a lógica do "tudo ou nada" própria das regras, na medida em que dependem de interações com outros princípios. Além disso, a sua relação com a moralidade pública autoriza a observação da comunidade política como indutora de normas jurídicas que podem ser utilizadas pelos tribunais para decidir as demandas que lhes são apresentadas (DIAS, 2016, p. 38).

Registre-se, ainda, que há uma diferença no que diz respeito à resolução de conflitos internos de cada categoria. Enquanto eventual conflito entre regras deve ser resolvido com a eliminação de uma delas ${ }^{4}$, nos princípios, que possuem dimensão de peso ou importância, é preciso lançar mão do recurso da relevância. Assim, num dado caso concreto, um determinado princípio pode não prevalecer, o que não significa que não se trate de um princípio do sistema jurídico, uma vez que, num outro caso concreto, quando as condições forem outras, esse mesmo princípio poderá ter um peso maior e ser decisivo (DWORKIN, 2007a, p. 41-43).

\subsection{AS POLÍTICAS COMO UM PADRÃO NORMATIVO E O SEU CONTROLE JUDICIAL}

No modelo pensado por Dworkin (2007a, p. 36) os princípios e as regras, de fato, têm uma posição de grande relevância, até porque o seu objetivo primeiro é negar a tese positivista de fundamentação exclusiva nas regras.

Embora atribua significativa importância aos princípios e às regras, Dworkin (2007 a, p. 36) admite outros padrões normativos e faz expressa referência às políticas. Observa-se,

\footnotetext{
${ }^{4}$ Vide os critérios de hierarquia, especialidade e cronologia, própria das regras de antinomia dispostas no Decreto-Lei n. 4.657 de 194, com redação dada pela Lei 12.376 de 2010, chamada de Lei de Introdução às Normas do Direito Brasileiro (LINDB).
} 
com isso, que o filósofo norte-americano introduziu as políticas como mais um padrão normativo do sistema jurídico, viabilizando a construção, a partir delas, de argumentos fortes para a resolução dos hard cases (Dias, 2016, p. 40).

Dworkin (2007a, p. 36) denomina de políticas o "tipo de padrão que estabelece um objetivo a ser alcançado ${ }^{5}$, em geral uma melhoria em algum aspecto econômico, político ou social". O conceito de políticas ainda está assentado em dois elementos, a saber: i) uma entidade capaz de produzir padrões à comunidade política; e ii) a identificação dos objetivos e o estabelecimento de meios que buscam alcançá-los.

A partir dessa conceituação, Dworkin estabelece como pressuposto da formulação de políticas uma regulação jurídica que as tornarão efetivas, possibilitando, assim, a orientação da conduta das autoridades com atribuição para as formular, permitindo, em consequência, o exercício de direitos por parte dos membros da comunidade política (DIAS, 2016, p. 40).

Isso leva à conclusão de que a realização das políticas está condicionada à adoção de um padrão jurídico capaz de introduzir no ambiente social uma série de objetivos que estabeleçam níveis de experiências sociais que serão tratadas, a partir de então, no campo jurídico (DIAS, 2016, p. 40).

Contudo, Dworkin (2007a, p. 132) rejeita a ideia do uso das políticas como orientadoras de decisões judiciais, até mesmo em hard case, posto que não admite argumentos consequencialistas como fundamento, o que importa dizer que as "as questões de alta complexidade devem ser decididas não pelos seus efeitos no plano social, mas pelos direitos que efetivamente as pessoas envolvidas realmente possuam” (DIAS, 2016, p. 43).

As políticas, conforme visto acima, são metas da comunidade como um todo, vinculadas a bens que são gerais. Os direitos, por sua vez, são individualizados e, portanto, a priori, não podem ser ultrapassados pelas políticas.

Mesmo assim, embora a formulação de políticas públicas seja atribuída precipuamente ao Poder Legislativo e ao Poder Executivo, sem qualquer intervenção do Poder Judiciário, isso não quer dizer que todo ou qualquer controle judicial não possa ser exercido sobre elas (as políticas públicas).

\footnotetext{
${ }^{5}$ Dworkin (2007a, p. 36) lembra que alguns objetivos podem ser inclusive negativos por estabelecerem que algum direito deve ser protegido contra mudanças adversas.
} 
Nas hipóteses em que as políticas públicas sejam capazes de provocar a violação de direitos, a questão se reveste na forma de um conflito jurídico, demandando, assim, uma intervenção $\left(\right.$ derivada $\left.^{6}\right)$ judicial com base em princípios.

Noutras palavras, apesar do Poder Judiciário não contribuir diretamente para a produção de políticas públicas, não se pode impedir que ele exerça o seu controle para fins de preservação de direitos fundamentais, que é sua missão institucional precípua.

Por isso, a definição de qualquer política pública precisa levar em conta a possibilidade de controle judicial em relação as suas repercussões jurídicas, até porque o combate à violação de direitos é uma questão que integra a função primeira do Poder Judiciário (DIAS, 2016, p. 52).

Vale dizer ainda, reforçando a tese do controle judicial, que as políticas públicas podem, concretamente, não representar o interesse da comunidade política, servindo apenas como subterfúgios para a proteção das classes dominantes, ou de minorias organizadas, ou ainda, para atender os interesses econômicos de grupos poderosos, sem, contudo, haver nenhum ganho social, e o que é pior, com o ferimento de direitos fundamentais.

Aliás, esse é a interpretação que, segundo Dias (2016, p. 57), melhor se coaduna com o modelo proposto por Dworkin quando ele analisa, por exemplo, o caso Mathews $v$. Eldridge, no qual a Suprema Corte norte-americana manteve o ato de cancelamento do benefício por invalidez outrora concedido pela Seguridade Social a um trabalhador que havia adquirido problemas nas costas e ansiedade, por considerar que a não realização de uma audiência prévia, como determinava a lei, não ofendia o direito ao devido processo legal pelo fato de que, supostamente, haviam inúmeros meios a disposição da Seguridade Social para evitar equívocos.

Dworkin (2005, p. 146-148) defendeu que a questão fosse submetida ao controle judicial, o que não necessariamente levaria a um resultado diferente, porque, nesse caso, a política pública comprometia o princípio ligado ao direito de evitar uma injustiça.

Por isso, Dias (2016, p. 57 e 158) defende que, havendo divergência entre os objetivos de uma política pública e direitos fundamentais, está configurada uma demanda que assume a forma de questão jurídica, carecendo de intervenção judicial, cuja decisão deve ser sustentada em princípios. Dessa maneira, amoldando-se ao pensamento de Dworkin, não se

\footnotetext{
${ }^{6}$ Dias (2016, p. 52) classifica como intervenção derivada aquela que depende da formulação prévia de uma política ou até mesmo de uma omissão, desde que haja o dever legal ou constitucional de produzi-la.
} 
pode dizer que os objetivos das políticas públicas devam ser recepcionados de forma neutra em relação a eventuais violações de direitos fundamentais, garantindo, inclusive, a também consagração de um sistema político equilibrado e amparado nas premissas de um Estado Democrático de Direito.

De se dizer que, nesse cenário, os tribunais assumem um papel de destaque na reflexão sobre as políticas, constituindo-se num verdadeiro exercício de revisão fundamental, alicerçado em direitos fundamentais, que se tornam o núcleo do sistema, restando ao Poder Judiciário a função de instrumento garantidor do Estado Democrático de Direito, sem que isso implique, necessariamente, em uma supressão dos outros dois poderes, na medida em que, como anteriormente dito, essa hipótese representa o regular exercício de sua função institucional de julgar casos concretos e manter a salvo os direitos fundamentais (DIAS, 2016, p. 159).

Os direitos fundamentais, portanto, devem ser o objetivo principal dos Estados contemporâneos, sendo que todos os poderes constituídos devem dirigir suas atuações para a implementação e preservação de tais direitos. Nesse sentido, Dias (2016, p. 161) sustenta que não devam existir atos insindicáveis, sob pena de se permitir arbitrariedades e, em consequência, golpes nos direitos fundamentais.

O controle judicial de políticas públicas, portanto, não representa uma violação a princípios democráticos. Muito pelo contrário: constitui, antes de mais nada, numa verdadeira garantia de proteção do cidadão frente ao Estado.

De se dizer, que na queda de braço entre uma política pública e um direito fundamental, o espectro da decisão não se reserva apenas ao campo político, mas se espraia também para o jurídico, e, por isso, deve ser baseada em princípios, garantindo a crítica e a invalidação racionais de uma determinada política pública pelo Poder Judiciário (DIAS, 2016, p. 190).

Com efeito, percebe-se a real possibilidade da atuação judicial frente a políticas publicas que contrariem direitos fundamentais. E isso vale também para a não implementação por parte, principalmente, do Poder Executivo, daquelas cuja não realização dá causa a violação desses direitos.

\section{A REFORMA AGRÁRIA}


Para Costa (2014, p. 74), reforma agrária significa uma verdadeira redistribuição da terra, não apenas uma alteração da estrutura fundiária e o modo pelo qual se distribui no espaço a propriedade da terra rural, mas também uma mudança na estrutura de posse e uso da terra por intermédio de uma modificação substancial no seu regime, com o advento de uma nova noção de propriedade, que deve ser caracterizada como um mecanismo de melhoria social não só para os que nela trabalham, mas também para toda a sociedade.

Costa (2014, p. 75) acredita que por envolver aspectos dos mais variados assuntos (político, econômico, sociológico, histórico, dentre outros), a definição de reforma agrária depende, sobremaneira, do momento histórico e da filosofia política adotada na ocasião num dado país, havendo concepções restritas e amplas de reforma agrária. As primeiras propugnam apenas a redistribuição da propriedade, enquanto que as segundas orientam-se pela implementação de um conjunto de medidas.

Assim, a depender das circunstâncias de momento, a reforma agrária pode significar: i) mera redistribuição da terra, exigindo uma política fundiária de planificação e organização com consequências de ordem ética e social; ou ii) de outro lado, uma verdadeira transformação do sistema de propriedades/posses e de exploração da terra, com a extinção de latifúndios e minifúndios e a implantação de um sistema justo de acesso e distribuição fundiária, com o surgimento de um novo estatuto jurídico que discipline a matéria a partir da orientação do cumprimento de sua função principal e mediante uma política agrícola que abra espaço para o crédito e assistência técnica.

Mattos Neto (2013, p. 12), filiando-se à ideia de reforma agrária ampla ou integral, a define como:

[...] a reestruturação da divisão do solo motivada pela concentração de terras em poder de poucos, que é a reforma fundiária, mas também a implementação e redefinição de políticas agrícolas e demais políticas públicas vinculadas ao setor que visem à fixação do homem no campo e seu desenvolvimento, como por exemplo, o incentivo fiscal, o crédito agrícola, a construção de infraestrutura com saneamento básico, transporte, energia, escolas, postos de saúde, armazéns e silos, estradas vicinais e etc. Como o programa deve ser integrado a outras ações e políticas governamentais, chama-se reforma agrária integral.

Do ponto de vista legislativo, a Lei n. 4.504 de 1964 (Estatuto da Terra) definiu, logo no seu artigo $1^{\circ}, \S 1^{\circ}$, o conceito de reforma agrária, estabelecendo como tal "o conjunto de medidas que visem a promover melhor distribuição da terra, mediante modificações no 
regime de sua posse e uso, a fim de atender os princípios de justiça social e ao aumento de produtividade" (BRASIL, 1964).

Diante disso, extrai-se que o termo reforma agrária reclama uma profunda alteração na estrutura agrária existente, com a formação de um novo ideal para a relação ser humanoterra-produção, a partir de um novo conceito para o direito de propriedade, fundado na utilização econômica da terra, com vantagem individual e social e, ainda, com respeito agroambiental, substituindo-se o latifúndio e o minifúndio por um sistema mais justo de acesso e distribuição fundiária, tudo para fins de atender os menos favorecidos e ao aumento da produtividade.

É imperioso deixar claro que o uso inadequado da terra ${ }^{7}$ traz embaraços e dificuldades ao desenvolvimento socioeconômico, o que dificulta o bem estar das pessoas, sobretudo do campesino, exigindo-se, assim, a implementação da reforma agrária como um processo de reestruturação da propriedade da terra, a fim de que: i) explorada de maneira racional, alcance a maior produtividade possível, permitindo a realização de uma melhor qualidade de vida e bem estar da sociedade; e ii) possa servir como instrumento de combate à concentração fundiária e à desigualdade social, proporcionando justiça social (distributiva) ${ }^{8}$ com o acesso dos menos favorecidos à terra.

Nesse sentido, o que se observa, pois, é que a reforma agrária se constitui em verdadeira política pública, no modelo pensado por Ronald Dworkin (2007 a, p. 36) como o "tipo de padrão que estabelece um objetivo a ser alcançado, em geral uma melhoria em algum aspecto econômico, político ou social da comunidade”.

\subsection{ASPECTO CONSTITUCIONAL E LEGAL}

Antes de mais nada, é importante deixar registrado que, embora a Constituição brasileira em voga garanta expressamente o direito à propriedade privada (artigo $5^{\circ}$, inciso XXII), não lhe confere caráter absoluto, na medida em que o condicionou ao cumprimento da sua função social (artigo $5^{\circ}$, inciso XXIII).

\footnotetext{
${ }^{7}$ Mattos Neto (2010) entende que o uso adequado passa pela utilização econômica da área, com racionalidade, a partir de um cultivo eficiente (respeitando-se a aptidão natural do solo com utilização de instrumento e tecnologia agrícola) e de uma exploração correta (observando-se as normas agrárias, trabalhistas, previdenciárias e ambientais), em área de terra que não se caracterize nem como latifúndio e nem como minifúndio.

${ }^{8}$ Samuel Fleischacker (2006, p. 3) coloca como sinônimos os termos justiça distributiva e justiça social.
} 
Na verdade, a Constituição brasileira reservou um capítulo inteiro (Capítulo III do Título VII) para tratar da reforma agrária, fixando no seu artigo 184 que compete exclusivamente à União promover a desapropriação de imóvel que não esteja cumprindo a sua função social, destinando-a, posteriormente, a essa política pública. Anotou também que a indenização será prévia e justa e em títulos da dívida agrária, com cláusula de preservação do valor real. Em seu artigo 185, a Constituição brasileira ainda exclui qualquer possibilidade de desapropriação para fins de reforma agrária da pequena e média propriedade rural - desde que seu proprietário não possua outra - e a propriedade produtiva, hipóteses essas a que se deve dar tratamento legislativo especial.

No âmbito infraconstitucional, o Estatuto da Terra, no artigo $2^{\circ}, \S 2^{\circ}$, estipula que o acesso à propriedade da terra é um dever (obrigação) do Estado (poder público) e isso deve ser realizado preferencialmente nas regiões onde o trabalhador rural habita. $\mathrm{O}$ artigo 16, também do estatuto da Terra estabeleceu que o objetivo da reforma agrária é criar um sistema de relações entre o homem, a propriedade rural e o uso da terra que autorize a promoção da justiça social, o progresso e o bem estar do trabalhador, além do desenvolvimento econômico, com a extinção progressiva do minifúndio e do latifúndio.

Desse modo, tem-se, sem qualquer sombra de dúvida, que a reforma agrária é, de fato, uma política que representa, no modelo de Ronald Dworkin, os anseios da comunidade política. Inclusive, a maneira como fora idealizada, pelo menos a nível constitucional e legal, revela uma melhoria multifacetada, pois tem reflexo direto em aspectos econômicos, políticos propriamente dito, e sociais.

\subsection{A REFORMA AGRÁRIA COMO DIREITO FUNDAMENTAL}

Os direitos fundamentais estão ligados aos bens jurídicos básicos da humanidade e a melhor forma de conceituá-los seria por intermédio da análise de sua fundamentalidade, decorrendo daí a importância da sua proteção formal e material.

$\mathrm{Na}$ fundamentalidade formal, vinculada ao direito constitucional positivo, há quatro características a serem destacadas: i) as normas fundamentais são postas no ápice da ordem jurídica; ii) por serem normas constitucionais estão submetidas aos procedimentos agravados de revisão; iii) constituem-se como limites materiais à revisão; iv) servem como diretrizes materiais para atuação dos poderes constituídos. 
Por sua vez, na fundamentalidade material tomam-se decisões sobre a estrutura básica do Estado e da comunidade política.

Com efeito, a fundamentalidade material é indispensável, uma vez que a própria concepção de fundamentalidade não pode ser restrita ao seu aspecto formal por dois motivos: i) seja porque apenas o aspecto material possa servir de base para a proteção de direitos também fundamentais, mas não protegidos formalmente; e ii) seja para o emprego aos direitos fundamentais materiais de recursos jurídicos previstos apenas em prol dos direitos fundamentais estritamente formais.

Além disso, a fundamentalidade material também é importante para assegurar a possibilidade de ingresso de novos direitos ainda não reclamados e descortinados, mas que tenham um conteúdo fundamental, até pela característica de incompletude da fundamentalidade formal.

É nesse sentido que Costa (2014, p. 103) atribui à reforma agrária a condição de um direito fundamental - diga-se, de fundamentalidade material -, já que importa em decisões sobre a estrutura do Estado e de toda a comunidade, mais precisamente quanto ao surgimento de uma nova concepção de propriedade, lastreado na função social e objetivando contribuir para o desenvolvimento humano nacional, diminuição da pobreza e desigualdades sociais.

Com a alteração na concepção de propriedade, esse direito que antes era tido como absoluto e ilimitado passou a ser submetido aos interesses sociais e coletivos, por intermédio do princípio da função social. Essa nova configuração do direito de propriedade, conforme já dito acima, foi consolidada na Constituição brasileira, mais precisamente, no artigo $5^{\circ}$, incisos XXII e XXIII. A partir dessa nova formatação, a propriedade assume a condição de bem voltado à geração de riquezas que deverão ser usufruídas não só pelo seu titular, mas também pela coletividade.

Para Costa (2014, p.104), a incorporação da função social ao conceito de propriedade implica num uso racional e equilibrado do bem (objeto do direito), objetivando proporcionar resultados positivos para toda a comunidade. E tanto isso é verdade que a Constituição brasileira, no artigo 170, que compõe o Título da Ordem Econômica e Financeira, condiciona a atividade econômica à finalidade de se assegurar a dignidade humana, sob as orientações da justiça social, observando-se, dentre outros, os princípios da propriedade privada e o da função social.

Nesse sentido, o que se tem é uma verdadeira imposição constitucional, de sorte que 
o proprietário não detém nenhuma margem para descumprimento, caracterizando-se, pois, a função social como um dever e a sua inobservância dá causa à desapropriação para fins de reforma agrária.

Ainda nas lições de Costa (2014, p. 105), os princípios da ordem econômica procuram harmonizar e compatibilizar os interesses privados (propriedade privada) aos públicos (função social), figurando a reforma agrária como um instrumento importante para a efetivação desse paradigma, conferindo ao Estado o poder-dever de implementar a renovação do conceito de propriedade, importando em mudanças na estrutura do Estado e da comunidade, assegurando-se a justiça social e o respeito à dignidade humana.

Pode-se dizer então que a reforma agrária é um direito fundamental em ambos os aspectos, formal e material.

\subsection{O CONTROLE JUDICIAL DA POLÍTICA DE REFORMA AGRÁRIA}

Conforme já visto na primeira seção, o sistema jurídico pensado por Dworkin é composto não só por regras emanadas de uma autoridade estatal, mas também por outros standards normativos, a exemplo de princípios e de políticas. Essas últimas, aliás, se constituem em verdadeiros objetivos/metas a serem perseguidos pelo Estado com repercussão positiva na seara econômica, política ou social.

Ocorre que a política pública da reforma agrária, que possui inclusive assento constitucional, vem sendo negligenciada pelo Poder Executivo que insiste em não realizá-la de modo amplo e efetivo (CARTER, 2010, p. 68-69).

Dessa inércia decorreu o crescimento de demandas judiciais a partir de conflitos fundiários e que têm como pano de fundo justamente a reforma agrária. A ocupação de terras no Brasil afora e, sobretudo, no Estado do Pará, se tornou uma realidade extremamente conflituosa, na qual o Poder Judiciário vem sendo, cada vez mais, instado a intervir.

Tanto é assim que o CNJ tem afirmando que:

O problema dos conflitos fundiários apresenta diversas nuances, pois envolve relações de poder, interesses econômicos e - hoje se sabe mais do que nunca aspectos ambientais. No entanto, o Poder Judiciário tem um papel pacificador relevante nesta área, não podendo se furtar de decidir os casos que lhe são submetidos, pois havendo o cumprimento dos pressupostos jurídicos e processuais 
as ações não julgadas podem, neste campo, representar o agravamento dos conflitos (BRASIL, 2009, p. 23).

No Estado do Pará, cujo o campo é o mais violento de todo o Brasil, nota-se que os conflitos fundiários se concentram na mesorregião do Sudeste Paraense, que reúne 84,54\% das famílias em conflito de terras no estado. Segundo o CNJ, dos 39 municípios desta mesorregião, 22 deles, ou seja, 56,41\%, foram palco deste tipo de conflito. Não por acaso o Índice de Desenvolvimento Humano (IDH) dessa mesorregião é um dos mais baixo do país, marcando exatos 0,69412 pontos, menor que a média estadual de 0,75513 pontos $^{9}$ (BRASIL, 2009, p. 39).

Diante de todo esse cenário, não houve outra saída que não a criação de Varas Agrárias junto ao Tribunal de Justiça do Estado do Pará, que foram reestruturadas depois da alteração da Lei Complementar Estadual n. 14 de 1993 (que dispõe sobre o Código de Organização Fundiária do Estado do Pará), para se adequar à Emenda Constitucional Estadual n. 30 de $2005^{10}$.

Mas não foi só no âmbito do Tribunal de Justiça do Estado do Pará que Varas Agrárias foram criadas. Segundo o CNJ, Varas Agrárias foram instituídas em outros dez Tribunais de Justiça ${ }^{11}$ e em dois Tribunais Regionais Federais ${ }^{12}$ (BRASIL, 2013).

\footnotetext{
${ }^{9}$ Merece destaque o município de Parauapebas, que apresenta "os índices mais elevados de registros de conflitos de terra. Um dos fatores que explicam o destaque negativo deste município está na sua própria constituição como município, visto que a então Vila de Parauapebas surgiu da implantação do Projeto Ferro Carajás, ocorrida em 1981. Houve então um aumento do fluxo migratório para esta região, se destacando a presença de madeireiros, garimpeiros e fazendeiros. A construção de ferrovias e rodovias, que facilitou o acesso à vila, colaborou com o aumento deste fluxo migratório, acarretando um aumento populacional elevado em pouco tempo, em menos de 23 anos a população aumentou mais de dez vezes, tendo o município um crescimento anual de 8,9\% no período de 1981 a 2004, enquanto o Brasil cresceu 1,3\% e o Pará, 2,0\%. Importante ressaltar que esta explicação é válida também para [...] entender melhor a situação em dois outros municípios com elevado número de famílias em conflitos, que são Canaã dos Carajás e Marabá. Enquanto Canaã dos Carajás era parte de Parauapebas, Marabá agregava área destes municípios até 1988. Outro destaque negativo nesta mesorregião é o município de Paragominas, local das primeiras companhias colonizadoras. Um fato interessante que pode ajudar na compreensão do alto índice de famílias em conflitos de terra nessa localidade seria a presença de empresários goianos antes mesmo das primeiras companhias colonizadoras. Esses empresários, com autorização do governo estadual, estavam nessa região com o objetivo de efetuar levantamentos e titular terras para compradores do triângulo mineiro. Com a construção da Rodovia Belém-Brasília, entre 1960 e 1974, a procura por essas terras aumentou consideravelmente tanto entre os mineiros como entre paulistas e capixabas. Os camponeses entraram em conflito com os migrantes que emitiam títulos falsos, sem deixar de lado o uso da força. Por fim, nos anos 1990 ocorreu uma significativa migração de sulistas na região" (CNJ, 2009, p. 39-40).

${ }_{10}$ Além das Varas Agrárias, foram criadas a Comissão de Mediação de Conflitos Fundiários vinculada ao Conselho Estadual de Segurança Pública e a Ouvidoria Agrária vinculada ao Tribunal de Justiça do estado do Pará (Decreto Estadual n. 2.410 de 1997) e 2002 (Lei Estadual n. 6.437 de 2002).

${ }^{11}$ Na Justiça estadual, já possuem Varas Agrárias os Tribunais de Justiça de Alagoas (TJAL), Amazonas (TJAM), Bahia (TJBA), Distrito Federal (TJDFT), Minas Gerais (TJMG), Mato Grosso (TJMT), Piauí (TJPI), Paraíba (TJPB), Rondônia (TJRO) e Santa Catarina (TJSC).
} 
As Varas Agrárias são responsáveis, por exemplo, pelo julgamento das ações possessórias coletivas e das ações de desapropriação por interesse social, para fins de reforma agrária. A solução dessas ações passa pelo enfrentamento, sob o ponto de vista jurídico, da precária implementação dessa política pública no Brasil, que embora contenha uma base política, não exclui o dever de se levar em consideração os princípios e regras do sistema jurídico que são ameaçados e violados por essa já mencionada precária implementação.

Anote-se que a não adoção de políticas públicas previstas constitucionalmente e que teriam o condão de promover os direitos fundamentais, a exemplo da reforma agrária, deve encontrar algum tipo de controle no Estado Democrático de Direito, sob pena de se permitir a realização de arbitrariedades.

A reforma agrária é direito fundamental e por isso deve ser implementada pelo Estado, prioritariamente pelo Poder Executivo.

No entanto, quando esse poder for omisso (como de fato está sendo) e quando houver uma demanda ajuizada que aborde de alguma forma esse tema, o Poder Judiciário deve intervir (intervenção derivada e em decorrência de uma omissão) no caso concreto e, com base em princípios, deliberar a respeito, promovendo a reforma agrária, ou seja, redistribuindo a terra, não apenas do ponto de vista de uma alteração da estrutura fundiária e do modo pelo qual se distribui no espaço a propriedade da terra rural, mas também permitindo uma mudança na estrutura de posse e uso da terra por intermédio de uma modificação substancial no seu regime. Possibilitando-se, portanto, o advento de uma nova noção de propriedade, caracterizada como um mecanismo de melhoria social não só para os que nela trabalham, mas também para toda a comunidade política.

Assim agindo, o Poder Judiciário estará atuando para equilibrar o sistema jurídico, que, conforme já visto, deve estar amparado num Estado Democrático de Direito, onde os direitos fundamentais têm papel de destaque e por isso devem ser a todo custo preservados.

Com efeito, o Poder Judiciário, considerando a omissão do executivo e para fins de preservar direitos fundamentais, não pode se furtar de, no caso concreto, promover a efetiva redistribuição de terra, sem que isso possa se caracterizar como uma usurpação das

\footnotetext{
${ }^{12}$ Na Justiça federal, instalaram Varas Agrárias as seções judiciárias do Amazonas, Bahia, Maranhão, Minas Gerais, Mato Grosso, Pará e Rondônia, todas do Tribunal Regional Federal da $1^{a}$ Região (TRF1), e a seção judiciária do Rio Grande do Sul, que integra o Tribunal Regional Federal da 4ª Região (TRF4).
} 
atribuições dos outros poderes, tudo com base nos princípios que constituem o sistema jurídico normativo, segundo as lições de Dworkin (2007a, p. 36).

\section{CONCLUSÃO}

O presente artigo buscou analisar em que medida a reforma agrária, da maneira como está disposta sua disciplina constitucional e legal, e diante da inércia sintomática do Poder Executivo em realizá-la, sob a luz da Teoria do Direito de Ronald Dworkin, pode ser implementada pelo Poder Judiciário nas decisões tomadas em casos concretos, por meio do controle judicial de políticas públicas.

Após toda a exposição, chega-se à conclusão que é possível responder afirmativamente ao problema apresentado, isto é, a reforma agrária pode ser levada a efeito pelo Poder Judiciário nos casos concretos que lhes são apresentados.

Essa conclusão se sustenta porque, conforme a análise dos vários problemas ocasionados pela desordem fundiária brasileira, reforma agrária se constitui, mais do que nunca, em um direito fundamental do cidadão e por isso deve ser implementada pelo Estado, por meio, a priori, do Poder Executivo, mas quando omisso, pelo Poder Judiciário, com base em princípios.

O controle judicial com relação à reforma agrária se dá através da redistribuição de terras com alteração da estrutura fundiária e do modo pelo qual se distribui no espaço a propriedade do imóvel rural, modificando-se, inclusive, a estrutura de posse e uso da terra por intermédio de uma alteração substancial no seu regime e com o advento de uma nova noção de propriedade, baseada no princípio da função social.

Portanto, quando houver divergência entre os objetivos de uma política pública (ou na omissão de sua implementação) e direitos fundamentais, estará configurada aí uma demanda que assume a forma de questão jurídica, reclamando, pois, a intervenção judicial, cuja decisão deve ser sustentada em princípios. Os objetivos das políticas públicas não podem ser recepcionados de forma neutra em relação a eventuais violações de direitos fundamentais, pois somente assim também consagrar-se-á um sistema político equilibrado e amparado nas premissas de um Estado Democrático de Direito. 
Diante disso, o Poder Judiciário assume uma função de destaque na reflexão sobre as políticas públicas, constituindo-se num verdadeiro exercício de revisão fundamental, sustentado em direitos fundamentais, que se tornam o núcleo do sistema jurídico.

\section{REFERÊNCIAS}

BRASIL. Conselho Nacional de Justiça. Relatório preliminar sobre a situação dos conflitos fundiários rurais no Brasil. Brasília: Departamento de Pesquisas Judiciárias, 2009.

BRASIL. Conselho Nacional de Justiça. Varas Agrárias. Disponível em: <http://www.cnj.jus.br/noticias/cnj/61158-onze-tjs-e-dois-trfs-possuem-varas-especializadasem-questoes-agrarias>. Acesso em: 10 jan. 2021.

BRASIL. Lei $\mathbf{n}^{\mathbf{0}}$ 4.504, de 30 de novembro de 1964. Dispõe sobre o Estatuto da Terra, e dá outras providências. Brasília, DF, 30 nov.1964. Disponível em: http://www.planalto.gov.br/ccivil_03/Leis/L6938.htm. Acesso em 03 abr. 2021.

BRASIL. Ministério do Meio Ambiente. A grilagem nas terras públicas da Amazónia brasileira. IPAM: Brasília: MMA, 2006.

CARTER, Miguel. Desigualdade social, democracia e reforma agrária no Brasil. In:

Combatendo a desigualdade social: O MST e a reforma agrária no Brasil. Tradução de Cristina Yamagami. São Paulo: Editora UNESP, 2010.

COSTA, Rosalina Moitta Pinto da. O direito fundamental à reforma agrária e seus instrumentos de concretização. Porto Alegre: Núria Fabris, 2014.

DIAS, Jean Carlos. O controle judicial de políticas públicas. Salvador: Juspodivm, 2016.

DWORKIN, Ronald. Levando os direitos a sério. Tradução de Nelson Boeira. São Paulo: Martins Fontes, 2007a.

DWORKIN, Ronald. Uma questão de princípio. Tradução de Luís Carlos Borges. São Paulo: Martins Fontes, 2005.

DWORKIN, Ronald. O império do direito. Tradução de Jefferson Luiz Camargo. São Paulo: Martins Fontes, 2007.

FLEISCHACKER, Samuel. Uma breve história da justiça distributiva. Tradução de Álvaro de Vita. São Paulo: Martins Fontes, 2006.

HART, H. L. A. O Conceito de Direito. Tradução de Antônio de Oliveira Sette-Câmara. São Paulo: Martins Fontes, 2009. 
MACEDO JUNIOR, Ronaldo Porto. Do xadrez à cortesia: Dworkin e a teoria do direito contemporânea. São Paulo: Saraiva, 2013.

MATTOS NETO, Antônio José. Estado de direito agroambiental brasileiro. São Paulo: Saraiva, 2010.

MATTOS NETO, Antônio José. Garantia do direito à propriedade agrária. In: BARROSO, Lucas Abreu et al (Org.). O direito agrário na Constituição. Rio de Janeiro: Forense, 2013. p. 1-23. 